\title{
Airway Pressure Release Ventilation Mode Improves Circulatory and Respiratory Function in Patients After Cardiopulmonary Bypass, a Randomized Trial
}

\begin{abstract}
Huiqing Ge ${ }^{1+}$, Ling Lin ${ }^{2 t}$, Ying $X u^{1}$, Peifeng $X u^{1}$, Kailiang Duan ${ }^{1}$, Qing $P^{2} n^{3}$ and Kejing Ying ${ }^{4 *}$
\end{abstract}

${ }^{1}$ Department of Respiratory Care, Regional Medical Center for National Institute of Respiratory Diseases, Sir Run Run Shaw Hospital, School of Medicine, Zhejiang University, Hangzhou, China, ${ }^{2}$ Department of Critical Care Medicine, Sir Run Run Shaw Hospital, School of Medicine, Zhejiang University, Hangzhou, China, ${ }^{3}$ College of Information Engineering, Zhejiang University of Technology, Hangzhou, China, ${ }^{4}$ Department of Respiratory and Critical Care, Regional Medical Center for National Institute of Respiratory Diseases, Sir Run Run Shaw Hospital, School of Medicine, Zhejiang University, Hangzhou, China

OPEN ACCESS

Edited by:

Zhanqi Zhao,

Furtwangen University, Germany

Reviewed by:

Daniel Rowley,

University of Virginia Health System,

United States

Lei Xu,

Chongqing Emergency Medical

Center, China

*Correspondence:

Kejing Ying

ykjsrrsh@zju.edu.cn

${ }^{\dagger}$ These authors share first authorship

Specialty section:

This article was submitted to Respiratory Physiology, a section of the journal Frontiers in Physiology

Received: 24 March 2021 Accepted: 10 May 2021

Published: 03 June 2021

Citation:

Ge H, Lin L, Xu Y, Xu P, Duan K,

Pan $Q$ and Ying K (2021) Airway Pressure Release Ventilation Mode Improves Circulatory and Respiratory Function in Patients After Cardiopulmonary Bypass, a Randomized Trial.

Front. Physiol. 12:684927. doi: 10.3389/fphys.2021.684927
Importance: Postoperative pulmonary complications and cardiovascular complications are major causes of morbidity, mortality, and resource utilization in cardiac surgery patients.

Objectives: To investigate the effects of airway pressure release ventilation (APRV) on respiration and hemodynamics in post cardiac surgery patients.

Main Outcomes and Measures: A single-center randomized control trial was performed. In total, 138 patients undergoing cardiopulmonary bypass were prospectively screened. Ultimately 39 patients met the inclusion criteria and were randomized into two groups: 19 patients were managed with pressure control ventilation (PCV) and 20 patients were managed with APRV. Respiratory mechanics after $4 \mathrm{~h}$, hemodynamics within the first day, and Chest radiograph score (CRS) and blood gasses within the first three days were recorded and compared.

Results: A higher cardiac index (3.1 \pm 0.7 vs. $\left.2.8 \pm 0.8 \mathrm{~L} \cdot \mathrm{min}^{-1} \cdot \mathrm{m}^{2} ; p<0.05\right)$, and shock volume index $\left(35.4 \pm 9.2\right.$ vs. $\left.33.1 \pm 9.7 \mathrm{ml} \mathrm{m}^{-2} ; p<0.05\right)$ were also observed in the APRV group after $4 \mathrm{~h}$ as well as within the first day $(p<0.05)$. Compared to the $\mathrm{PCV}$ group, the $\mathrm{PaO} 2 / \mathrm{FiO}_{2}$ was significantly higher after $4 \mathrm{~h}$ in patients of APRV group $(340 \pm 97$ vs. $301 \pm 82, p<0.05)$ and within the first three days $(p<0.05)$ in the APRV group. CRS revealed less overall lung injury in the APRV group $(p<0.001)$. The duration of mechanical ventilation and ICU length of stay were not significantly $(p=0.248$ and 0.424 , respectively).

Conclusions and Relevance: Compared to PCV, APRV may be associated with increased cardiac output improved oxygenation, and decreased lung injury in postoperative cardiac surgery patients.

Keywords: mechanical ventilation, airway pressure release ventilation, cardiopulmonary bypass, circulatory function, respiratory function 


\section{INTRODUCTION}

Postoperative pulmonary complications and cardiovascular complications are major causes of morbidity, mortality and resource utilization in cardiac surgery patients (Biccard et al., 2018). Patients undergoing cardiopulmonary bypass (CPB) frequently experience hypoxemia and pulmonary complications after surgery and may develop acute respiratory distress syndrome (Cox et al., 2000; Stephens et al., 2013). The passage of blood through the $\mathrm{CPB}$ circuit can activate inflammatory and coagulation pathways (Al Jaaly et al., 2015), which may lead to poor postoperative gas exchange and lung mechanics, an increase in the pulmonary shunt fraction and a reduction in functional residual capacity. Despite the advanced CPB techniques and the preventive measures used to avoid respiratory complications after cardiac surgery (Apostolakis et al., 2010; García-Delgado et al., 2014), postoperative acute respiratory distress syndrome manifests in 10-20\% of patients (Gajic et al., 2011), and its overall mortality remains high (Habashi and Andrews, 2004; Kor et al., 2014). In addition, improper postoperative ventilator settings are associated with an increased risk for lung infection, a longer duration of intubation and a longer hospital stay (Wolthuis et al., 2008).

Airway pressure release ventilation (APRV) mode is a lung protective strategy that has been proposed to treat refractory hypoxemic respiratory failure while preventing ventilator-induced lung injury (Gary et al., 2017). APRV was originally described as a mode to treat acute lung injury in patients and attempt to maintain the level of airway pressure without reducing cardiac function, delivering mechanical breaths without excessive airway pressure and allowing unrestricted spontaneous ventilation. The potential benefits include decreased sedation, a shorter duration of mechanical ventilation, and an improvement in cardiac performance (Mireles-Cabodevila and Kacmarek, 2016). However, APRV introduces a higher mean airway pressure (Pmean) compared to conventional ventilation mode, which may increase intrathoracic pressure, and subsequently right atrial pressure. Hence, APRV might lead to a decrease in systemic venous return compared to conventional mechanical ventilation. Some studies have reported the effect of APRV on the respiratory and circulatory system in patients with ARDS, but there are few reports on the patients after cardiac surgery (Garner et al., 1988; Kaplan et al., 2001). We hypothesized that APRV could result in better outcomes in postoperative care of such population. A randomized controlled trial was designed to compare APRV with conventional PCV.

\footnotetext{
Abbreviations: $\mathrm{CPB}$, cardiopulmonary bypass; APRV, Airway pressure release ventilation; Pmean, airway mean pressure; PCV, pressure control ventilation; ICU, Intensive care unit; $\mathrm{FiO}_{2}$, fraction of inspired oxygen; CVP, Central venous pressure; PAWP, pulmonary artery wedge pressure; $\mathrm{SvO}_{2}$, mixed venous oxygen saturation; $\mathrm{SpO}_{2}$, peripheral capillary oxygen saturation; $\mathrm{P}_{\text {plat }}$, plateau pressure; $\mathrm{PaO}_{2}$, arterial partial pressure of $\mathrm{O}_{2} ; \mathrm{PaCO}_{2}$, partial pressure of arterial carbon dioxide; RM, alveolar recruitment maneuver; CRS, Chest radiographic scores; PVR, pulmonary vascular resistance; $\mathrm{DO}_{2}$, oxygen delivery; $\mathrm{VO}_{2}$, oxygen consumption.
}

\section{MATERIALS AND METHODS}

\section{Study Design and Setting}

This study protocol was approved by the Medical Ethics Committee of Sir Run Run Shaw Hospital and Zhejiang University School of Medicine (20181225-6). Written informed consent was obtained from all patients or their legal representatives prior to the study. The clinical trial number was ISRCTN92666776.

\section{Participants}

Consecutive patients scheduled for cardiac surgery and afterward referred to the intensive care unit (ICU) from March 1st to May 31 st, 2020 were included in the study. The exclusion criteria were age less than 18 years, history of chronic obstructive pulmonary disease, or asthma, mechanical ventilation prior to the operation, use of a mechanical device to maintain hemodynamics prior to the operation and extubation within $30 \mathrm{~min}$ after surgery (Figure 1). All patients were placed on mechanical ventilation. Patients who met all the inclusion criteria were randomly assigned to the PCV group or the APRV group Randomization was achieved with computer-generated random numbers, which were then stored in sealed envelopes.

\section{Anesthesia and Perioperative Management}

Anesthetic technique was standardized. Endotracheal tubes and radial artery and pulmonary artery catheters were inserted after the induction of anesthesia. During anesthesia, patients were ventilated with volume-controlled ventilation (Fabius GS Premium, Germany) with the following settings: a tidal volume of $8 \mathrm{ml} / \mathrm{kg}$, respiratory rate of 12 breaths per min, positive end-expiratory pressure (PEEP) of $5 \mathrm{cmH}_{2} \mathrm{O}$ and fraction of inspired oxygen $\left(\mathrm{FiO}_{2}\right)$ of $50 \%$. Subsequently, the anesthesia was maintained with a continuous infusion of fentanyl and propofol, and rocuronium was used as a paralytic. The CPB was established via a standard median sternotomy, aortic root cannulation, and single or double atrial cannulation for venous return. CPB flow was kept between 2.2 and $2.5 \mathrm{l} / \mathrm{min} / \mathrm{m}^{2}$ with a target mean perfusion pressure of $60 \mathrm{mmHg}$. If necessary, norepinephrine was administered to reach the targeted blood pressure. Weaning from $\mathrm{CPB}$ was initiated once the patient's cardiac rhythm had stabilized and normothermia had been achieved. Standard clinical postoperative care with goal-directed therapy was initiated after separating the patient from the $\mathrm{CPB}$ machine and was continued during the ICU stay to maintain hemodynamic stability. The central venous pressure (CVP) was kept between 10 and $12 \mathrm{mmHg}$ and pulmonary artery wedge pressure (PAWP) between 15 and $18 \mathrm{mmHg}$ by the administration of intravenous fluids. Inotropic support with epinephrine was initiated in order to maintain a cardiac index (CI) greater than $2.2 \mathrm{l} / \mathrm{min} / \mathrm{m}^{2}$. Milrinone was administered if epinephrine was increased to a maximum of $0.1 \mu \mathrm{g} / \mathrm{kg} / \mathrm{min}$ and additional inotropy was needed. The target mean arterial blood pressure was set at $>65 \mathrm{mmHg}$ and norepinephrine was administered if necessary. Lactate was targeted at $<2 \mathrm{mmol} / \mathrm{L}$ 


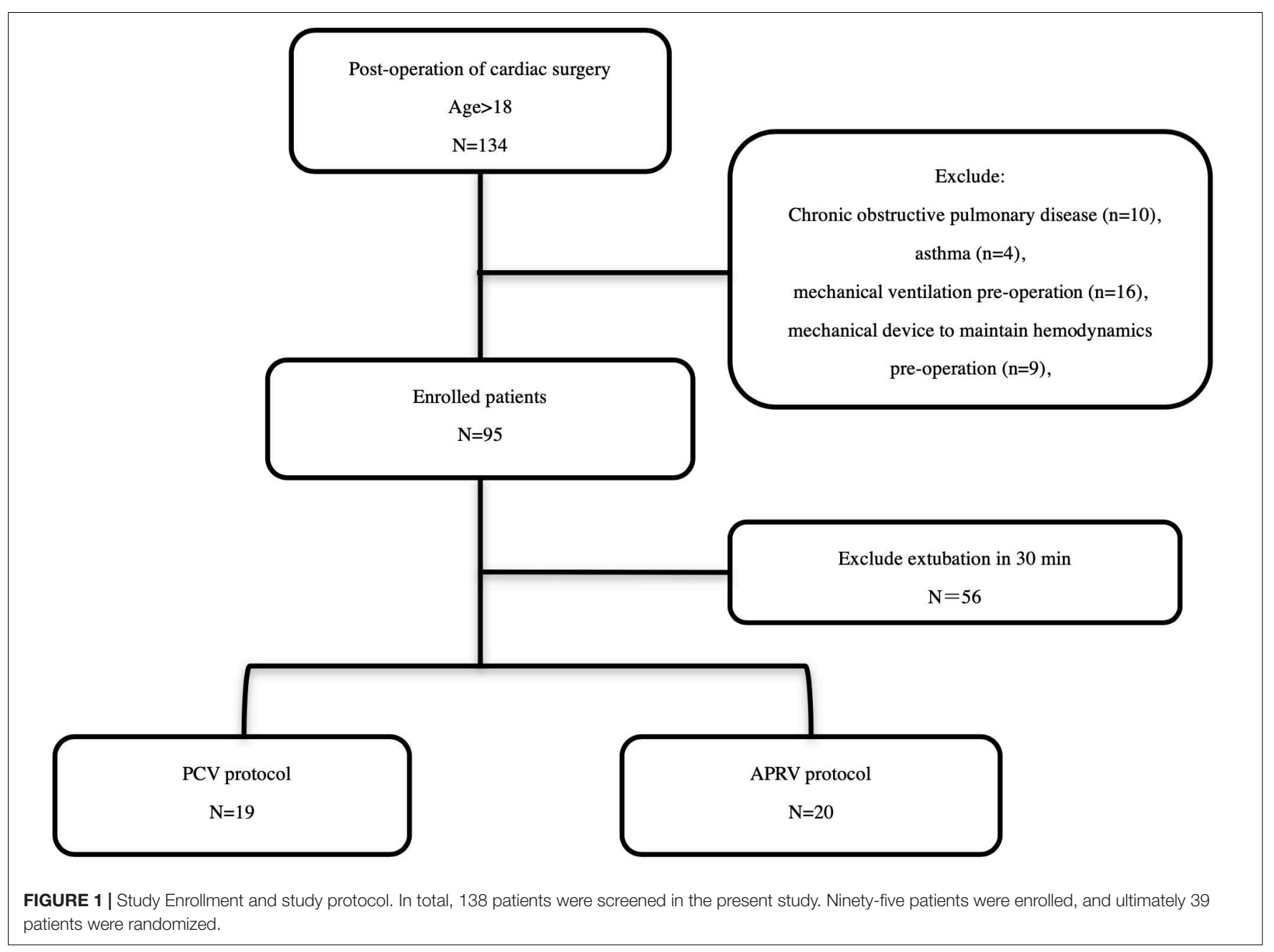

and mixed venous oxygen saturation $(\mathrm{SvO} 2)$ at $>70 \%$. An intra-aortic balloon pump was inserted if further support was required. Hemoglobin was maintained at $>70 \mathrm{~g} / \mathrm{L}$ with transfusion of packed red blood cells. The decision to weaning patients from inotropic and vasopressor medications was made by the attending ICU physicians based on the assessment of hemodynamic data, urine output and physical status. These physicians were blinded in our study. Pain medication was used in all patients to maintain a pain scale score less than three points, as measured by a numerical rating scale or the Critical Care Pain Observational Tool (Rijkenberg et al., 2015). Patients were discharged from the ICU when the following criteria were met: stable hemodynamics without any vasoactive agents, peripheral capillary oxygen saturation $(\mathrm{SpO} 2)>94 \%$ at an $\mathrm{FiO}_{2}<0.5$ by facemask, chest tube drainage $<200 \mathrm{~mL}$ within the past $8 \mathrm{~h}$, and urine output $>0.5 \mathrm{~mL} / \mathrm{kg} / \mathrm{h}$.

\section{Ventilation Protocol}

\section{Baseline Settings}

After admission to the ICU, patients were connected to Evita 4 ventilators (Dräger Medical, Lübeck, Germany). All patients were ventilated with volume-controlled ventilation in assist control mode for the first $30 \mathrm{~min}$. The tidal volume was set to 6$8 \mathrm{ml} / \mathrm{kg}$ per kilogram of predicted body weight according to the plateau pressure (Pplat) (to maintain Pplat $<30 \mathrm{~cm} \mathrm{H} \mathrm{H}_{2} \mathrm{O}$ ); the Pplat measured during conventional ventilation by using the ventilator's inspiratory pause control. The levels of PEEP and $\mathrm{FiO}_{2}$ were based on the patient's underlying clinical condition to obtain an SpO2 of 90\%-95\% or an arterial partial pressure of $\mathrm{O} 2$ $\left(\mathrm{PaO}_{2}\right)$ of $60-80 \mathrm{mmHg}$. The respiratory rate was set to maintain a partial pressure of arterial carbon dioxide $\left(\mathrm{PaCO}_{2}\right)$ between 35 and $45 \mathrm{mmHg}$. A stepwise maximum alveolar recruitment maneuver $(\mathrm{RM})$ was performed in all patients.

\section{RM Process}

This process was accomplished as follows: the mechanical ventilator was set to $\mathrm{PCV}$ mode with $\mathrm{FiO}_{2}$ of $100 \%$, a respiratory rate of 12/min and an I: E ratio of 1:1. An incremental PEEP trial was performed starting at a pressure of $10 \mathrm{cmH}_{2} \mathrm{O}$ with steps of $5 \mathrm{cmH}_{2} \mathrm{O}$ and a duration of $1 \mathrm{~min}$ per step until the peak pressure reached $45 \mathrm{cmH}_{2} \mathrm{O}$. The driving pressure was set to $15 \mathrm{cmH}_{2} \mathrm{O}$. The duration of the highest step was $2 \mathrm{~min}$ instead of 1 . The $\mathrm{RM}$ was stopped if one or more of the following signs of clinical deterioration were observed: heart rate $\geq 140$ or $<60$ bpm; MBP 
$<65 \mathrm{mmHg}$ or systolic blood pressure $<90 \mathrm{mmHg}$; SpO2 $<88 \%$ or $5 \%$ decreased from baseline; or acute atrial fibrillation, atrial flutter or ventricular tachycardia (Dean, 2015).

\section{Ventilation in the PCV Group}

After the RM, the driving pressure was adjusted to match the value at baseline. Appropriate adjustments to the respiratory rate were made to maintain $\mathrm{PaCO}_{2}$ between 35 and $45 \mathrm{mmHg}$. The $\mathrm{PEEP}$ and $\mathrm{FiO}_{2}$ were adjusted in response to changes in the $\mathrm{SpO} 2$ along the "Lower PEEP/Higher $\mathrm{FiO}_{2}$ " scale (The Acute Respiratory Distress Syndrome Network, 2000; Kasenda et al., 2016). The Pplat was kept below $30 \mathrm{cmH}_{2} \mathrm{O}$.

\section{Ventilation in the APRV Group}

In the APRV group, the ventilator mode was switched to APRV with the following initial settings: The PHigh was initially set to the Pplat at baseline. The PLow was set to $0 \mathrm{cmH}_{2} \mathrm{O}$. The duration of the PHigh (THigh) was set to 3.6-6.0 s (minimal $90 \%$ of the total respiratory cycle time). The duration of the release phase (TLow) was set to terminate at $75 \%$ of the peak expiratory flow rate. This parameter was calculated and monitored for adjustment based on the angle of deceleration noted on the expiratory flow waveform. The PHigh, THigh, TLow and $\mathrm{FiO}_{2}$ were titrated based on interpretation of the expiratory flow waveform and arterial blood gasses (Garner et al., 1988; Habashi, 2005).

\section{Cardiovascular Measurements}

Heart rate, mean arterial systemic blood pressure (MAP), CVP, mean pulmonary artery pressure (PAP), and PAWP, end diastolic velocity (EDV), pulmonary vascular resistance index (PVRI), cardiac output (CO), CI, and stroke volume (SV) were measured (intelivue MP60, Philips, Netherlands) and recorded (SwanGanz, Arrow Company, United States). The Swan-Ganz catheter was removed after the first ICU day after hemodynamics stability was confirmed.

\section{Respiratory Mechanics and ABG Measurements}

The baseline respiratory mechanics were recorded at once the patients admitted to ICU and connected to the ventilator (T0), $1 \mathrm{~h}$ after mechanical ventilation (T1), and $4 \mathrm{~h}$ after mechanical ventilation (T2). Dynamic lung mechanics were calculated by the ventilators. PEEPi measurement was performed with endexpiratory occlusion. The Pplat was measured with a breath holding technique at the end of inspiration when the patients were sedated maintained Richmond at a Agitation Sedation Scale (Rass) score of -2 . The mean airway pressure was calculated by the ventilator as the geometric mean of the pressure-time curve. Arterial blood gasses were examined every $4 \mathrm{~h}$ on the first day and once every morning on days 2-3 (GEM Premier 3000, IL, United States). The central laboratory of Sir Run Run Shaw Hospital performed clinical pathology tests and blood cultures.

\section{Chest Radiograph Score}

Chest radiograph score (CRS) (Antonio et al., 2005) were obtained pre-operatively and $1 \mathrm{~h}, 1$ day, and 3 days postoperatively. Anterior chest radiographs were assessed (Model X-ray tube assembly 0.7/1.3U163C-36, SHIMADZU Corporation, Japan) using a standardized technique $(70 \mathrm{kV}$, $3.8 \mathrm{mAs}, 100 \mathrm{~cm}$ film-focus distance for anteroposterior; broad tube focus for both). Each lung zone was evaluated by scoring the radiographs with a four-point scale based on visual assessment (Antonio et al., 2005; Habashi, 2005) as follows: $0=$ normal (no alveolar consolidation), 1 = alveolar consolidation confined to 1 quadrant, 2 = alveolar consolidation confined to 2 quadrants, and 3 = alveolar consolidation confined to 3 quadrants, $4=$ alveolar consolidation in 4 quadrants. Radiologists independently evaluate chest $\mathrm{x}$-ray. In addition to the information evident on the radiographs, the radiologists were blinded to the group assignment, clinical progress and final outcomes of the patients.

\section{Data Collection and Statistical Analysis}

The primary endpoints of the study were the effects of APRV on cardiorespiratory function, including lung mechanics, blood gasses and CRS within 3 days, and hemodynamic parameters within 1 day. The secondary endpoint was the duration of mechanical ventilation and ICU stay.

Data were tested for normal distribution with the Shapiro-Wilks $W$-test. The results were expressed as the means \pm standard deviations. For blood gasses and hemodynamics, data were analyzed by two-way analysis of variance (ANOVA), with the ventilation mode and time after randomization as independent variables. Differences between the means were analyzed separately with a post hoc Newman-Keuls multiple comparison test. Baseline demographics and respiratory mechanics of the two groups were compared using two-tailed unpaired Student's t-tests or chi-squared tests, where applicable. Differences were considered statistically significant for results with $p<0.05$.

\section{RESULTS}

\section{Patient Characteristics}

In total, 134 patients were screened in the present study. Ninety-five patients were enrolled, and ultimately 39 patients were randomized (Figure 1). The types of surgery were: mitral valve replacements (26/39), tricuspid valve repairs $(5 / 39)$, aortic valve replacements (2/39), coronary artery bypass graft $(5 / 39)$, and cardiac tumor resection (1/39). The mean age was $56.0 \pm 14.7$ years, male/female was 18/21. The baseline characteristics of the patients are summarized in Table 1. No statistically significant differences were found between the two study groups at baseline.

\section{Hemodynamics and Laboratory Data}

The APRV and PCV groups demonstrated hemodynamic stability during mechanical ventilation. MAP, MPAP, and CVP changes did not differ between groups at any measurement time points (Table 2). The increase in the CI and SI were significantly higher with APRV than with PCV after $4 \mathrm{~h}(p=0.017$ and $p=0.024$, respectively). PVRI and right ventricular work 
TABLE 1 | Patient demographics and baseline parameters.

\begin{tabular}{|c|c|c|c|}
\hline Parameter & APRV $(N=20)$ & $\operatorname{PCV}(N=19)$ & $p$-value \\
\hline Age, year & $55 \pm 15$ & $58 \pm 15$ & 0.45 \\
\hline Sex, M/F & $11 / 9$ & $7 / 12$ & 0.26 \\
\hline APACHE ॥ & $14 \pm 5$ & $17 \pm 8$ & 0.24 \\
\hline $\begin{array}{l}\text { EuroSCORE ॥ } \\
\text { Disease, } n \text { (\%) }\end{array}$ & $7.5 \pm 4.4$ & $7.4 \pm 8.2$ & 0.98 \\
\hline Valve repair or replacement & $17(85)$ & $16(84)$ & 0.99 \\
\hline CABG & $2(10)$ & $3(15)$ & 0.95 \\
\hline $\begin{array}{l}\text { Resection of a cardiac tumor } \\
\text { Smoking, } n(\%)\end{array}$ & $1(5)$ & $0(0)$ & \\
\hline Yes & $12(60)$ & $11(57.9)$ & 0.89 \\
\hline No & $8(40)$ & $8(42.1)$ & \\
\hline Operation time, min & $261.4 \pm 86.6$ & $238.4 \pm 94.4$ & 0.43 \\
\hline CPB time, min & $139.2 \pm 67.3$ & $119.4 \pm 71.3$ & 0.85 \\
\hline Clamping time, min & $101 \pm 48.6$ & $81.1 \pm 45.0$ & 0.89 \\
\hline Cst $\left(\mathrm{ml} / \mathrm{cmH}_{2} \mathrm{O}\right)$ & $43.4 \pm 13.5$ & $42.7 \pm 7.1$ & 0.84 \\
\hline $\mathrm{R}\left(\mathrm{cmH}_{2} \mathrm{O} /(\mathrm{L} \cdot \mathrm{s})\right)$ & $12.7 \pm 3.6$ & $8.9 \pm 1.4$ & 0.32 \\
\hline
\end{tabular}

APACHE, Acute Physiology and Chronic Health Evaluation II; CABG, coronary artery bypass grafting; CPB, cardiopulmonary bypass; Cst, static compliance; $R$, resistance. Values are expressed as means $\pm S D$.

(RVSW) were lower in the APRV group ( $p=0.028$ and $p=0.002$, respectively).

\section{Pulmonary Mechanics and Gas Exchange}

Most of the patients $(85.7 \%)$ were extubated before $8 \mathrm{~h}$. The compliance and resistance were calculated by the ventilator with using least squares Regression. The ID of the endotracheal tube was $8.0 \mathrm{~mm}$ for males and $7.5 \mathrm{~mm}$ for females. There was no significant difference between the PCV and APRV groups in lung compliance and airway resistance or other baseline pulmonary characteristics. Patients in the PCV group had a higher peak airway pressure (PCV vs. APRV, $15.7 \pm 2.1$ vs. $18 \pm 2.2, p=0.000$ ) and Pplat (PCV vs. APRV, $18.5 \pm 2.9$ vs. $16.3 \pm 3.8, p=0.000$ ) after randomization. The Pmean was significantly higher in the APRV group than in the PCV group after transition from assistcontrol ventilation ( $p=0.000$ ) (Table 3). Cst after $4 \mathrm{~h}$ was higher in the APRV group ( $p=0.001$, Table 3$)$.

A higher $\mathrm{PaO}_{2} / \mathrm{FiO}_{2}(p=0.002)$ and central venous oxygen saturation $\left(\mathrm{ScrO}_{2}, p=0.013\right)$ were found in the APRV group compared to the PCV group after $4 \mathrm{~h}$. Arterial $\mathrm{pH}, \mathrm{PaCO}_{2}$, and $\mathrm{SaO}_{2}$ were comparable in the two groups (Table 4). The lactate level was higher in the PCV group $(p=0.000)$. CRS was improved in the APRV group compared to the PCV group $(p=0.001$, Table 5).

\section{Mechanical Ventilation Time and ICU Stay}

The duration of mechanical ventilation was lower, but not significantly lower, in the APRV groups $(14.3 \pm 16.0$ vs. $18.4 \pm 20.7 \mathrm{~h}, \mathrm{APRV}$ vs. PCV, respectively; $p=0.248$ ). The ICU length of stay was not significantly different $(59.5 \pm 39.3 \mathrm{vs}$, $79.6 \pm 52.6 \mathrm{~h}, \mathrm{APRV}$ vs. PCV, respectively; $p=0.424$ ) (Table 6).

\section{DISCUSSION}

Airway pressure release ventilation made effects of lung mechanics, hemodynamics and blood gasses in post cardiac surgery patients. Compared with PCV, we found that APRV may be associated with higher Cst, $\mathrm{PaO}_{2} / \mathrm{FiO}_{2}$ and $\mathrm{ScvO}_{2}$, increased $\mathrm{CI}$ and improved CRS. This study is the first randomized trial demonstrating the potential benefit of APRV in patients after cardiac surgery.

Right ventricular (RV) failure post cardiac surgery increases morbidity and mortality (Bhama et al., 2018). Lung collapse induced by general anesthesia and CPB may increase RV outflow impedance by activation of the hypoxic pulmonary vasoconstriction reflex and by the geometrical changes of pulmonary capillaries with atelectasis, regardless of mild local hypoventilation or complete atelectasis (Brismar et al., 1985; Moudgil et al., 2005). In our study, cardiac surgery resulted in increased PVR and decreased PA compliance, both known to negatively affect RV performance. Since high PAP and PVR significantly contribute to RV dysfunction, it seems reasonable to apply a ventilation strategy using APRV mode to reverse pulmonary atelectasis and minimize both PAP and PVR to protect both the lungs and the right ventricle.

Classic physiology states that PVR has a U-shaped relationship with lung volume, its lowest value corresponding to functional residual capacity. According to Shekerdemian (Shekerdemian and Bohn, 1999), PVR, the major determinant of RV afterload, is related to lung volume in a bimodal fashion. The total resistance of the pulmonary circulation depends on the balance in the vascular tone of its two components: the alveolar vessels and the extra-alveolar or parenchymal vessels. Furthermore, atelectasis gives rise to intrapulmonary shunting (perfused but nonventilated lung regions) and subsequent hypoxia. Overdistension, on the other hand, causes dead space ventilation (ventilated but non-perfused lung regions), leading to hypercapnia. Both hypercapnia and hypoxia increase PVR and RV afterload (Lynch et al., 1979; Mekontso Dessap et al., 2009). In our study, in the APRV group, PVR decreased significantly compared to the PCV group $(p<0.05)$. APRV may ameliorate lung collapse, increases lung volume and decreases PVR.

Numerous animal and clinical studies have shown that venous return is often sustained during ventilation with PEEP (Jansen and Versprille, 1986; Johnson and Normann, 1989). Potentially, PEEP-induced diaphragmatic descent increases abdominal pressure. van den Berg and Pinsky (2002) found that, in hemodynamically stable fluid-resuscitated postoperative surgical patients, inspiratory-hold maneuvers with a Pplat increase up to $20 \mathrm{~cm} \mathrm{H} \mathrm{H}_{2} \mathrm{O}$ have minimal effects on $\mathrm{CO}$, primarily because during the inspiratory phase, the abdominal compartment is pressurized causing compression of the liver and the lungs. Thus, with normal blood volume, increased intrathoracic pressure in a certain range does not lead to a significant decrease in blood pressure. In our research, standard clinical postoperative care with goal-directed therapy was used to maintain hemodynamic stability. Therefore, despite the higher mean airway pressure in the APRV group, the MAP and MPAP were similar to those in the PCV 
TABLE 2 | Hemodynamics parameters.

\begin{tabular}{|c|c|c|c|c|c|c|}
\hline Variables & Group & Baseline & $4 h$ & $8 \mathrm{~h}$ & $1 \mathrm{~d}$ & $p$-value \\
\hline \multirow[t]{2}{*}{ HR (beats/min) } & PCV & $85.8 \pm 9.9$ & $86.1 \pm 11.6$ & $87.2 \pm 9.6$ & $85.7 \pm 10.0$ & 0.308 \\
\hline & APRV & $90.0 \pm 13.7$ & $90.6 \pm 13.7$ & $88.4 \pm 11.9$ & $85.0 \pm 14.2$ & \\
\hline \multirow[t]{2}{*}{ MAP (mmHg) } & PCV & $85 \pm 11$ & $79 \pm 11$ & $74 \pm 6$ & $73 \pm 6$ & 0.743 \\
\hline & APRV & $81 \pm 11$ & $77 \pm 9$ & $78 \pm 7$ & $79 \pm 9$ & \\
\hline \multirow[t]{2}{*}{ MPAP (mmHg) } & PCV & $24.9 \pm 9.1$ & $22.4 \pm 5.5$ & $23.1 \pm 4.4$ & $24.1 \pm 4.8$ & 0.527 \\
\hline & APRV & $26.2 \pm 5.5$ & $23.6 \pm 4.6$ & $23.3 \pm 4.7$ & $24.2 \pm 5.7$ & \\
\hline \multirow[t]{2}{*}{ CVP $(\mathrm{mmHg})$} & PCV & $11.1 \pm 2.6$ & $9.9 \pm 3.4$ & $11.5 \pm 2.8$ & $11.3 \pm 2.8$ & 0.59 \\
\hline & APRV & $10.6 \pm 2.0$ & $10.4 \pm 2.6$ & $10.1 \pm 2.1$ & $12.3 \pm 2.4$ & \\
\hline \multirow[t]{2}{*}{$\mathrm{Cl}\left(\mathrm{L} \cdot \mathrm{min}^{-1} \cdot \mathrm{m}^{2}\right)$} & PCV & $2.8 \pm 0.8$ & $2.8 \pm 0.8$ & $2.5 \pm 0.7^{\#}$ & $2.7 \pm 0.4$ & 0.017 \\
\hline & APRV & $2.8 \pm 0.7$ & $3.1 \pm 0.7^{\star \# \#}$ & $2.9 \pm 0.5^{\star}$ & $3.1 \pm 0.5^{\star \#}$ & \\
\hline \multirow[t]{2}{*}{$\mathrm{SI}\left(\mathrm{ml} \cdot \mathrm{m}^{-2}\right)$} & PCV & $32.6 \pm 10.0$ & $33.1 \pm 9.7$ & $29.0 \pm 9.2$ & $31.7 \pm 7.7$ & 0.024 \\
\hline & APRV & $33.3 \pm 7.1$ & $35.4 \pm 9.2^{\star \#}$ & $35.3 \pm 7.4^{\star \#}$ & $37.2 \pm 6.4^{\star \#}$ & \\
\hline \multirow[t]{2}{*}{ PVRI (dyne $\left.\cdot \mathrm{s} \cdot \mathrm{cm}^{-5} \cdot \operatorname{Min} \cdot \mathrm{m}^{2}\right)$} & PCV & $338.4 \pm 169.5$ & $339.2 \pm 179.4$ & $296.5 \pm 85.3^{\#}$ & $286.9 \pm 125.1^{\#}$ & 0.028 \\
\hline & APRV & $315.1 \pm 147.3^{\star}$ & $248.3 \pm 91.3^{\star \#}$ & $222.2 \pm 100.3^{\star \#}$ & $215.1 \pm 105.0^{\star \#}$ & \\
\hline \multirow[t]{2}{*}{ SVRI (dyne $\left.\cdot \mathrm{s} \cdot \mathrm{cm}^{-5} \cdot \mathrm{Min} \cdot \mathrm{m}^{2}\right)$} & PCV & $2334 \pm 843$ & $2079 \pm 826$ & $2165 \pm 499$ & $1901 \pm 347$ & 0.096 \\
\hline & APRV & $2258 \pm 478$ & $1814 \pm 527$ & $1903 \pm 398$ & $1851 \pm 500$ & \\
\hline \multirow[t]{2}{*}{ PAWP (mmHg) } & PCV & $14.2 \pm 5.2$ & $12.6 \pm 2.9$ & $14.3 \pm 3.7$ & $14.8 \pm 3.0$ & 0.007 \\
\hline & APRV & $15.6 \pm 4.9$ & $15.1 \pm 4.6$ & $15.8 \pm 3.8$ & $16.2 \pm 3.6$ & \\
\hline
\end{tabular}

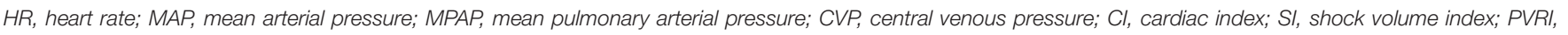
pulmonary vascular resistance index; SVRI, systemic vascular resistance index; PAWP, pulmonary artery wedge pressure. Values are expressed as means \pm SD. ${ }^{*} p<0.05$ APRV vs. PCV at the same time; ${ }^{\#} p<0.05$ vs. baseline in the same group.

TABLE 3 | Ventilator settings after randomization after $4 \mathrm{~h}$ and respiratory mechanics after 1 and $4 \mathrm{~h}$.

\begin{tabular}{|c|c|c|c|c|c|}
\hline Variables & Group & Baseline & $4 \mathrm{~h}$ & $8 \mathrm{~h}$ & $p$-value \\
\hline \multirow[t]{2}{*}{ Cstat $\left(\mathrm{ml} / \mathrm{cmH}_{2} \mathrm{O}\right)$} & PCV & $42 \pm 7$ & $49 \pm 11$ & $41 \pm 8$ & 0.008 \\
\hline & APRV & $43 \pm 9$ & $49 \pm 9^{\#}$ & $52 \pm 11^{\star \#}$ & \\
\hline \multirow[t]{2}{*}{$\operatorname{Rinsp}\left(\mathrm{cmH}_{2} \mathrm{O}\right) /(\mathrm{L} \cdot \mathrm{s})$} & PCV & $9 \pm 1$ & $10 \pm 2$ & $7 \pm 2$ & 0.302 \\
\hline & APRV & $9 \pm 2$ & $13 \pm 9$ & $8 \pm 2$ & \\
\hline \multirow[t]{2}{*}{ Pplat $\left(\mathrm{cmH}_{2} \mathrm{O}\right)$} & PCV & $19 \pm 3$ & $18 \pm 3$ & $18 \pm 3$ & 0.004 \\
\hline & APRV & $16 \pm 3^{*}$ & $16 \pm 3^{\star}$ & $15 \pm 3^{\star}$ & \\
\hline \multirow[t]{2}{*}{$P_{\text {mean }}\left(\mathrm{cmH}_{2} \mathrm{O}\right)$} & PCV & $9 \pm 2$ & $9 \pm 3$ & $9 \pm 2$ & 0.002 \\
\hline & APRV & $11 \pm 3^{\star}$ & $13 \pm 2^{*}$ & $11 \pm 2^{*}$ & \\
\hline \multirow[t]{2}{*}{ Ppeak $\left(\mathrm{cmH}_{2} \mathrm{O}\right)$} & PCV & $18 \pm 2$ & $18 \pm 3$ & $19 \pm 3$ & 0.000 \\
\hline & APRV & $15 \pm 2^{*}$ & $16 \pm 3^{*}$ & $15 \pm 3^{*}$ & \\
\hline \multirow{2}{*}{ PEEPtotal $\left(\mathrm{cmH}_{2} \mathrm{O}\right)$} & PCV & $6 \pm 2$ & $6 \pm 2$ & $6 \pm 1$ & 0.075 \\
\hline & APRV & $5 \pm 1$ & $5 \pm 1$ & $5 \pm 1$ & \\
\hline \multirow[t]{2}{*}{$\mathrm{DP}\left(\mathrm{cmH}_{2} \mathrm{O}\right)$} & PCV & $13 \pm 2$ & $14 \pm 2$ & $13 \pm 2$ & 0.000 \\
\hline & APRV & $12 \pm 2$ & $10 \pm 3^{\star}$ & $10 \pm 5^{\star}$ & \\
\hline \multirow[t]{2}{*}{$\mathrm{VT}(\mathrm{L})$} & PCV & $0.48 \pm 0.06$ & $0.50 \pm 0.08$ & $0.49 \pm 0.08$ & 0.457 \\
\hline & APRV & $0.48 \pm 0.07$ & $0.47 \pm 0.08$ & $0.49 \pm 0.11$ & \\
\hline
\end{tabular}

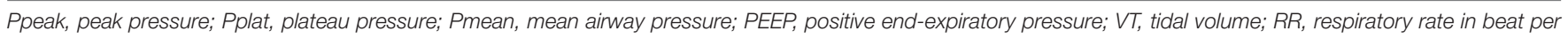
minute; Cst, static compliance; $R$, resistance. Values are expressed as means $\pm S D$.

${ }^{*} p<0.05$ APRV vs. PCV at the same time; ${ }^{\#} p<0.05$ vs. baseline in the same group.

group. The CI was higher in the APRV group (Table 2). During the treatment, the Phigh setting was titrated with MAP and oxygen. After cardiac surgery, PVR increased in patients who developed lung collapse and pulmonary oedema. Cardiopulmonary interaction ensures that with the right intrathoracic pressure and appropriate tidal volume, the lowest PVR can be reached. At the same time, increased intrathoracic pressure reduces left ventricular afterload. These combined factors are beneficial in increasing the CI.
Spontaneous breathing was associated with an increase in CI. This finding is in agreement with the concept that a decrease in intrathoracic pressure during spontaneous inspiration with APRV may improve venous return and CI (Lee et al., 2017). Our protocol targeted CVP and PAWP as well. In our patients, SVO2 were improved as a result of improved CI. Increased oxygen delivery with unchanged oxygen consumption resulted in an improved relationship between tissue oxygen supply and demand, which may also 
TABLE 4 | Arterial Blood gasses analysis.

\begin{tabular}{|c|c|c|c|c|c|c|c|c|}
\hline Variables & Group & Baseline & $4 h$ & $8 \mathrm{~h}$ & 1 days & 2 days & 3 days & $p$ \\
\hline \multirow[t]{2}{*}{$\mathrm{PH}$} & PCV & $7.36 \pm 0.10$ & $7.31 \pm 0.07$ & $7.31 \pm 0.06$ & $7.32 \pm 0.05$ & $7.36 \pm 0.06$ & $7.40 \pm 0.03$ & 0.785 \\
\hline & APRV & $7.35 \pm 0.08$ & $7.34 \pm 0.06$ & $7.31 \pm 0.07$ & $7.34 \pm 0.08$ & $7.34 \pm 0.04$ & $7.38 \pm 0.05$ & \\
\hline \multirow[t]{2}{*}{$\mathrm{PaCO}_{2}(\mathrm{mmHg})$} & PCV & $35 \pm 12$ & $35 \pm 7$ & $35 \pm 7$ & $37 \pm 8$ & $45 \pm 9^{\#}$ & $43 \pm 6^{\#}$ & 0.030 \\
\hline & APRV & $39 \pm 8$ & $36 \pm 5$ & $38 \pm 4$ & $38 \pm 6$ & $47 \pm 10^{\#}$ & $44 \pm 5^{\#}$ & \\
\hline \multirow[t]{2}{*}{$\mathrm{HCO}_{3}(\mathrm{mmol} / \mathrm{L})$} & PCV & $20 \pm 4$ & $18 \pm 4$ & $17 \pm 4$ & $19 \pm 5$ & $24 \pm 3$ & $24 \pm 2$ & 0.074 \\
\hline & APRV & $21 \pm 2$ & $19 \pm 3$ & $19 \pm 3$ & $20 \pm 3$ & $24 \pm 3$ & $25 \pm 4$ & \\
\hline \multirow[t]{2}{*}{$\mathrm{P} / \mathrm{F}$ ratio } & PCV & $284 \pm 86$ & $301 \pm 82$ & $312 \pm 76$ & $292 \pm 84$ & $231 \pm 62$ & $268 \pm 55$ & 0.002 \\
\hline & APRV & $292 \pm 86$ & $340 \pm 97^{\star \#}$ & $352 \pm 81^{\star \#}$ & $334 \pm 74^{\star \#}$ & $284 \pm 93^{\star}$ & $306 \pm 71^{*}$ & \\
\hline \multirow[t]{2}{*}{$\mathrm{P}(\mathrm{A}-\mathrm{a}) \mathrm{DO}_{2}(\mathrm{mmHg})$} & PCV & $131 \pm 48$ & $103 \pm 55$ & $107 \pm 46$ & $110 \pm 50$ & $132 \pm 47$ & $107 \pm 38$ & 0.162 \\
\hline & APRV & $121 \pm 40$ & $104 \pm 47$ & $90 \pm 38$ & $101 \pm 42$ & $115 \pm 63$ & $97 \pm 51$ & \\
\hline \multirow[t]{2}{*}{ Lactate (mmol/L) } & PCV & $5.22 \pm 3.54$ & $6.76 \pm 3.43$ & $7.45 \pm 3.67$ & $6.36 \pm 4.24$ & $3.06 \pm 1.72$ & $2.05 \pm 1.30$ & 0.000 \\
\hline & APRV & $3.18 \pm 2.77$ & $4.23 \pm 2.67$ & $5.32 \pm 3.74$ & $4.59 \pm 3.46$ & $2.58 \pm 0.80$ & $1.63 \pm 0.67$ & \\
\hline \multirow[t]{2}{*}{$\mathrm{ScVO}_{2}(\%)$} & PCV & $58 \pm 14$ & $56 \pm 13$ & $50 \pm 16$ & $49 \pm 8$ & $61 \pm 6$ & $66 \pm 5^{\#}$ & 0.013 \\
\hline & APRV & $60 \pm 13$ & $64 \pm 12^{\star \#}$ & $61 \pm 12^{*}$ & $58 \pm 9^{\star}$ & $66 \pm 6^{\star \#}$ & $70 \pm 4^{\star \#}$ & \\
\hline
\end{tabular}

Values are expressed as means $\pm S D$. ${ }^{*} p<0.05 \mathrm{APRV}$ vs. PCV at the same time; ${ }^{*} p<0.05$ vs. baseline in the same group. P/F ratio $=$ PaO $2 / \mathrm{FiO}_{2}$ ratio.

TABLE 5 | Chest radiograph score (CRS).

\begin{tabular}{llcllll}
\hline Variables & Group & $\begin{array}{c}\text { Baseline } \\
\text { (pre-operation) }\end{array}$ & 1 day & 2 days & $\mathbf{3}$ days & $\boldsymbol{p}$ \\
\hline CRS (\%) & PCV & $0.6 \pm 0.9$ & $1.2 \pm 0.7$ & $1.6 \pm 0.8$ & $1.1 \pm 0.8$ & 0.001 \\
& APRV & $0.4 \pm 0.7$ & $0.8 \pm 0.8$ & $0.6 \pm 0.8$ & $0.4 \pm 0.8$ & \\
\hline
\end{tabular}

CRS, Chest radiographic scores. Values are expressed as means $\pm S D$.

TABLE 6 | Mechanical ventilation time.

\begin{tabular}{lcccc}
\hline Parameter & APRV & PCV & $\boldsymbol{t}$ & $\boldsymbol{p}$-value \\
\hline MV Time (h) & $14.3 \pm 16.0$ & $18.4 \pm 20.7$ & 0.699 & 0.248 \\
ICU length of stay(h) & $59.5 \pm 39.3$ & $79.6 \pm 52.6$ & 1.357 & 0.424 \\
\hline
\end{tabular}

Values are means $\pm S D$.

have contributed to the higher $\mathrm{PaO}_{2}$ during APRV with spontaneous breathing.

\section{The Effect of APRV on Respiratory Mechanics}

Airway pressure release ventilation maintains a sustained Paw over a large proportion of the respiratory cycle, and therefore this ventilation strategy has a high pressure-time profile (Lynch et al., 1979). The pathologic tetrad of permeability, edema, surfactant deactivation and alveolar instability are the early drivers of postoperative lung pathology in the setting of cardiac surgery. We hypothesized the early introduction of APRV would specifically target these key elements of post cardiac surgery lung pathophysiology and prevent lung function injury. The recruitment of alveolar units is known to be a function of both ventilator pressure and time (Jansen and Versprille, 1986). APRV had a significantly higher Pmean than PCV due to the extended time at the Phigh, and had a lower Ppeak and Pplat than PCV (Table 3). Compared to the application of PCV with higher PEEP, which requires a tidal volume above PEEP in order to ventilate,
APRV described as CPAP with a brief release, releases pressure from the Phigh in order to generate a ventilatory volume. APRV can harness the potential energy contained within the elastic properties of the respiratory system that cause the lung to recoil naturally to generate the tidal volume (Neumann et al., 2005; Güldner et al., 2014). The data suggest that rather than overdistending alveoli, the extended THigh /PHigh redistributes gas from the alveolar ducts to the alveoli, where it belongs (Schiller et al., 2001; Santos et al., 2005), and converts heterogeneous alveolar ventilation to homogeneous alveolar ventilation (Seah et al., 2011). Thus, the extended inspiratory duration has a powerful positive impact on reducing strain at the alveolar level.

Transpulmonary pressure could be used to evaluate the driving pressure and confirm the appropriate parameters settings. Due to the financial issues and the invasiveness of the operation, transpulmonary pressure was not routinely monitored, which was a limitation of the present study. The driving pressures of the two groups were the same, but the area under the pressuretime curve, which is defined as pressure/time profile $(\mathrm{P} / \mathrm{Tp})$, was different (Roy et al., 2013). APRV maintains a sustained airway pressure over a large proportion of the respiratory cycle, and therefore, this ventilation strategy has a higher $\mathrm{P} / \mathrm{Tp}$, which improved alveolar recruitment, reduced oedema and subsequently improved oxygenation (improved the $\mathrm{P} / \mathrm{F}$ ratio). Early intervention using a ventilator mode with a high P/TP was recommended to prevent ARDS (MacDonnell et al., 2012; Roy et al., 2013).

Chest radiograph score assesses the extent of pulmonary exudative lesions by bilateral lung infiltration images. Our study found CRS was lower in the APRV group compared to PCV group, suggesting that the range of exudative lesions is smaller.

Limitations of our study include the fact that the number of patients enrolled was not large enough for stratification analysis. The baseline difference in the lactate level could have been caused by the small sample size. Our current data did not suggest the application of APRV would have significantly reduced the MV and ICU length of stay. Limited sample size in the present study 
could be one of the reasons for this finding. Urine output was not recorded after cardiac surgery. Although urine output is a non-invasive, primary variable for understanding the $\mathrm{CO}$, it is often insufficient for hemodynamic evaluation, rapid assessment, and the identification of occult or compensated shock (Suess and Pinsky, 2015). The duration of ventilation was shorter in the APRV group but not significantly shorter. Since no previous studies provided information regarding the differences between APRV and PCV, we could not accurately calculate the effective sample size. The post hoc power for lung mechanics, $\mathrm{P} / \mathrm{F}$ ratio and CRS indicated varied from $27.4 \%$ ( $\mathrm{P} / \mathrm{F}$ ratio at $4 \mathrm{~h}$ ) to 78.0\% (CRS at day 3). With the current findings we hope to provide information for a priori sample size calculation for future multi-centered randomized control trials.

In conclusion, compared to PCV, APRV may be associated with increased CO, improved oxygenation, and decreased lung injury after post operation of cardiac surgery.

\section{DATA AVAILABILITY STATEMENT}

The original contributions presented in the study are included in the article/supplementary material, further inquiries can be directed to the corresponding author/s.

\section{REFERENCES}

Al Jaaly, E., Zakkar, M., and Florentino, F. (2015). Pulmonary Protection Strategies in Cardiac Surgery: Are We Making Any Progress? Oxid. Med. Cell Longev. 2015:416235.

Antonio, G. E., Wong, K. T., Tsui, E. L., Chan, D. P., Hui, D. S., Ng, A. W., et al. (2005). Chest Radiograph Scores as Potential Prognostic Indicators in Severe Acute Respiratory Syndrome (SARS). Am. J. Roentgenol. 184, 734-741. doi: 10.2214/ajr.184.3.01840734

Apostolakis, E. E., Koletsis, E. N., Baikoussis, N. G., Siminelakis, S. N., Papadopoulos, G. S., et al. (2010). Strategies to prevent intraoperative lung injury during cardiopulmonary bypass. J. Cardiothorac. Surg. 5:1.

Bhama, J. K., Bansal, U., Winger, D. G., Teuteberg, J. J., Bermudez, C., Kormos, R. L., et al. (2018). Clinical experience with temporary right ventricular mechanical circulatory support. J. Thorac. Cardiovasc. Surg. 156, 1885-1891. doi: 10.1016/j.jtcvs.2018.04.094

Biccard, B. M., Madiba, T. E., and Kluyts, H. L. (2018). Perioperative patient outcomes in the African Surgical Outcomes Study: a 7-day prospective observational cohort study. Lancet 391, 1589-1598.

Brismar, B., Hedenstierna, G., Lundquist, H., Strandberg, A., Svensson, L., Tokics, L., et al. (1985). Pulmonary densities during anaesthesia with muscular relaxation: a proposal of atelectasis. Anesthesiology 62, 422-428. doi: 10.1097/00000542-198504000-00009

Cox, C. M., Ascione, R., Cohen, A. M., Davies, I. M., Ryder, I. G., and Angelini, G. D. (2000). Effect of cardiopulmonary bypass on pulmonary gas exchange: a prospective randomized study. Ann. Thorae. Surg. 69, 140-145. doi: 10.1016/ s0003-4975(99)01196-0

Dean, R. H. (2015). Recruitment Maneuvers and PEEP Titration. Respir. Care 60, 1688-1704. doi: 10.4187/respcare.04409

Gajic, O., Dabbagh, O., Park, P. K., Adesanya, A., Chang, S. Y., Hou, P., et al. (2011). Early identification of patients at risk of acute lung injury: evaluation of lung injury prediction score in a multicenter cohort study. Am. J. Respir. Crit. Care Med. 183, 462-470. doi: 10.1164/rccm.201004-0549oc

García-Delgado, M., Navarrete-Sánchez, I., and Colmenero, M. (2014). Preventing and managing perioperative pulmonary complications following cardiac surgery. Curr. Opin. Anaesthesiol. 27, 146-152. doi: $10.1097 /$ aco.0000000000000059

\section{ETHICS STATEMENT}

The studies involving human participants were reviewed and approved by the Ethics Committee of Sir Run Run Shaw hospital. The patients/participants provided their written informed consent to participate in this study.

\section{AUTHOR CONTRIBUTIONS}

HG and KY designed the study. HG and LL drafted the manuscript with input from all authors. YX, PX, and $\mathrm{KD}$ were responsible for collecting clinical data. QP analyzed the data with input from all authors. All authors contributed to the interpretation of the data and approved the final of the manuscript.

\section{ACKNOWLEDGMENTS}

We are grateful to the medical team of surgical ICU and cooperative staffs of respiratory care department in Sir Run Run Shaw Hospital.

Garner, W., Downs, J. B., Stock, M. C., and Rasanen, J. (1988). Airway pressure release ventilation (APRV): a human trial. Chest 94, 779-781. doi: 10.1378/ chest.94.4.779

Gary, F. N., Joshua, S., and Penny, A. (2017). Personalizing mechanical ventilation according to physiologic parameters to stabilize alveoli and minimize ventilator induced lung injury. Intens. Care Med. Exp. 5:8.

Güldner, A., Braune, A., Carvalho, N., Beda, A., Zeidler, S., Wiedemann, B., et al. (2014). Higher levels of spontaneous breathing induce lung recruitment and reduce global stress/strain in experimental lung injury. Anesthesiology 120, 673-682. doi: 10.1097/aln.0000000000000124

Habashi, N. M. (2005). Other approaches to open-lung ventilation: airway pressure release ventilation. Crit. Care $\mathrm{Med}$. 33, S228-S240.

Habashi, N., and Andrews, P. (2004). Ventilator strategies for posttraumatic acute respiratory distress syndrome: airway pressure release ventilation and the role of spontaneous breathing in critically ill patients. Curr. Opin. Crit. Care. 10, 549-557. doi: 10.1097/01.ccx.0000145473.01597.13

Jansen, J. R. C., and Versprille, A. (1986). Improvement of cardiac output estimation by thermodilution method during mechanical ventilation. Intens. Care Med. 12, 71-79. doi: 10.1007/bf00254515

Johnson, R. W., and Normann, R. A. (1989). Central venous blood tem- perature fluctuations and thermodilution signal processing in dogs. Ann. Biomed. Eng. 17, 657-669. doi: 10.1007/bf02367469

Kaplan, L. J., Bailey, H., and Formosa, V. (2001). Airway pressure release ventilation increases cardiac performance in patients with acute lung injury/adult respiratory distress syndrome. Crit. Care 5, 221-226.

Kasenda, B., Sauerbrei, W., Royston, P., Mercat, A., Slutsky, A. S., Cook, D., et al. (2016). Multivariable fractional polynomial interaction to investigate continuous effect modifiers in a meta-analysis on higher versus lower PEEP for patients with ARDS. BMJ Open 6:e011148. doi: 10.1136/bmjopen-2016-011148

Kor, D. J., Lingineni, R. K., Gajic, O., Park, P. K., Blum, J. M., Hou, P. C., et al. (2014). Predicting risk of postoperative lung injury in high-risk surgical patients: a multicenter cohort study. Anesthesiology 120, 1168-1181. doi: 10. 1097/aln.0000000000000216

Lee, M., Curley, G. F., Mustard, M., and Mazer, C. D. (2017). The SwanGanz Catheter Remains a Critically Important Component of Monitoring in Cardiovascular Critical Care. Can. J. Cardiol. 33, 142-147. doi: 10.1016/j.cjca. 2016.10.026 
Lynch, J. P., Mhyre, J. G., and Dantzker, D. R. (1979). Influence of cardiac output on intrapulmonary shunt. J. Appl. Physiol. 46, 315-321. doi: 10.1152/jappl.1979. 46.2.315

MacDonnell, S. M., Kubo, H., Crabbe, D. L., Renna, B. F., Reger, P. O., Mohara, J., et al. (2012). Early Stabilizing Alveolar Ventilation Prevents ARDS- A Novel Timing-Based Ventilatory Intervention to Avert Lung Injury. J. Trauma. Acute Care Surg. 73, 391-400. doi: 10.1097/ta.0b013e31825c7a82

Mekontso Dessap, A., Charron, C., Devaquet, J., Aboab, J., Jardin, F., Brochard, L., et al. (2009). Impact of acute hypercapnia and augmented positive endexpiratory pressure on right ventricle function in severe acute respiratory distress syndrome. Intens. Care Med. 35, 1850-1858. doi: 10.1007/s00134-0091569-2

Mireles-Cabodevila, E., and Kacmarek, R. M. (2016). Should Airway Pressure Release Ventilation Be the Primary Mode in ARDS. Respir. Care 61, 761-773. doi: 10.4187/respcare.04653

Moudgil, R., Michelakis, E. D., and Archer, S. L. (2005). Hypoxic pulmonary vasoconstriction. J. Appl. Physiol. 98, 390-403.

Neumann, P., Wrigge, H., Zinserling, J., Hinz, J., Maripuu, E., Andersson, L. G., et al. (2005). Spontaneous breathing affects the spatial ventilation and perfusion distribution during mechanical ventilatory support. Crit. Care Med. 33, 10901095. doi: 10.1097/01.ccm.0000163226.34868.0a

Rijkenberg, S., Stilma, W., Bosman, R. J., van der Meer, N. J., van der Voort, P. H. J., et al. (2015). Pain measurement in mechanically ventilated critically ill patients: behavioral pain scale versus critical-care pain observation tool. J. Crit. Care 30, 167-172. doi: 10.1016/j.jcrc.2014.09.007

Roy, S., Habashi, N., Sadowitz, B., Andrews, P., Ge, L., Wang, G., et al. (2013). Early airway pressure release ventilation prevents ARDS-a novel preventive approach to lung injury. Shock 39, 28-38. doi: 10.1097/shk.0b013e31827b $47 \mathrm{bb}$

Santos, C. C., Zhang, H., Liu, M., and Slutsky, A. S. (2005). Bench-to-bedside review: biotrauma and modulation of the innate immune response. Crit. Care 9, 280-286.

Schiller, H. J., McCann, U. G. II, Carney, D. E., Gatto, L. A., Steinberg, J. M., Nieman, G. F., et al. (2001). Altered alveolar mechanics in the acutely injured lung. Crit. Care Med. 29, 1049-1055. doi: 10.1097/00003246-200105000-00036
Seah, A. S., Grant, K. A., Aliyeva, M., Allen, G. B., and Bates, J. H. (2011). Quantifying the roles of tidal volume and PEEP in the pathogenesis of ventilator-induced lung injury. Ann. Biomed. Eng. 39, 1505-1516. doi: 10.1007/ s10439-010-0237-6

Shekerdemian, L., and Bohn, D. (1999). Cardiovascular effects of mechanical ventilation. Arch. Dis. Child. 80, 475-480.

Stephens, R. S., Shah, A. S., and Whitman, G. J. (2013). Lung injury and acute respiratory distress syndrome after cardiac surgery. Ann. Thorac. Surg. 95, $1122-11129$.

Suess, E. M., and Pinsky, M. R. (2015). Hemodynamic Monitoring for the Evaluation and Treatment of Shock: What Is the Current State of the Art? Semin. Respir. Crit. Care Med. 36, 890-898. doi: 10.1055/s-0035-1564874

The Acute Respiratory Distress Syndrome Network (2000). Ventilation with lower tidal volumes as compared with traditional tidal volumes for acute lung injury and the acute respiratory distress syndrome. N. Engl. J. Med. 342, 1301-1308. doi: 10.1056/nejm200005043421801

van den Berg, P. C., and Pinsky, M. R. (2002). Effect of positive pressure on venous return in volume-loaded cardiac surgical patients. J. Appl. Physiol. 92, 1223-1231. doi: 10.1152/japplphysiol.00487.2001

Wolthuis, E. K., Choi, G., Dessing, M. C., Bresser, P., Lutter, R., Dzoljic, M., et al. (2008). Mechanical Ventilation with Lower Tidal Volumes and Positive End-expiratory Pressure Prevents Pulmonary Inflammation in Patients without Preexisting Lung Injury. Anesthesiology 108, 46-54. doi: 10.1097/01.anes. 0000296068.80921 .10

Conflict of Interest: The authors declare that the research was conducted in the absence of any commercial or financial relationships that could be construed as a potential conflict of interest.

Copyright (c) $2021 \mathrm{Ge}$, Lin, Xu, Xu, Duan, Pan and Ying. This is an open-access article distributed under the terms of the Creative Commons Attribution License (CC BY). The use, distribution or reproduction in other forums is permitted, provided the original author(s) and the copyright owner(s) are credited and that the original publication in this journal is cited, in accordance with accepted academic practice. No use, distribution or reproduction is permitted which does not comply with these terms. 